\title{
Stability Determination
}

National Cancer Institute

\section{Source}

National Cancer Institute. Stability Determination. NCI Thesaurus. Code C134030.

For determination of maintained performance parameters on storage over time, of a material, drug or a drug substance. 